\title{
Railroad impacts on wetland habitat: GIS and modeling approach
}

\author{
Subhro Mitra \\ University of North Texas at Dallas \\ Subhro.mitra@unt.edu
}

\author{
Achintya N. Bezbaruah \\ North Dakota State University \\ a.bezbaruah@ndsu.edu
}

\begin{abstract}
Deepor Beel is one of the most important wetlands in the Brahmaputra Valley of lower Assam in India and is representative of the wetlands found within the Burma Monsoon Forest biogeography region. Deepor Beel is a Wetland of International Importance under the Ramsar Convention and is contiguous with Rani and Garbhanga reserved forests. These forests house endangered Asiatic elephants (Elephas maximus) in addition to other birds and animals. The elephants depend on the wetland for water and food. Indian Railways constructed Assam state's southern railroad through the wetland in 2001. The railroad has fragmented the wetland into at least two subsystems and has segregated the wetland-forest ecosystem. Accelerated degradation of elephant habitat has been observed in the wetland since the railroad was constructed. Further, a number of elephants have died because of collisions with rail traffic. This study quantifies the impacts of the present railroad on the Deepor Beel ecosystem with special reference to Asiatic elephants. Geographic information systems (GIS) and mathematical models are used in impact quantification. The tools developed in this study can be used in analyses of similar ecosystems around the world.
\end{abstract}

\section{$1 \quad$ Introduction}

Wetlands are among the most productive ecosystems in the world and are associated with the environmental, social, and economic wellbeing of society (Brander et al. 2006; Reinelt et al. 1991). Wetlands provide a number of ecosystem services; the average annual value of the global ecosystem services of wetlands is estimated at US $\$ 4,879$ billion (Constanza et al. 1997). Wetlands serve as important wildlife refuges and support a number of wildlife species by supplying food, water, and shelter. They also provide livelihood and nutrition to the local human population. Wetlands play important roles in groundwater recharge and discharge, flood flow alteration, sediment stabilization, water quality, food chain support, fisheries, and heritage (Maltby 1991). Each wetland has its own local, regional, and global importance in terms of ecological and socioeconomic values (Gurluke and Rehber 2006). Because of their unique role in the ecosystem and in society, the International Ramsar Convention on Wetlands (Ramsar 2008a) provides a framework for national action and international cooperation for the conservation and judicious use of wetlands and their resources. One hundred sixty countries are signatories to the Ramsar convention. As of 2010, 1897 wetlands ( 186 million hectares) throughout the world are designated for inclusion in the Ramsar List of Wetlands of International Importance (Ramsar 2008b). Inclusion on the Ramsar list also calls for active steps from the respective governments for the protection and enrichment of the specific Ramsar wetland.

Transportation is recognized as one of the basic needs for human development. However, rapid urbanization and the concomitant increase in transportation infrastructure have adversely affected the world's ecosystems. Due consideration to the ecosystem during transportation planning can increase the ecological relevance of transportation infrastructure to a great extent (Jabareen 2006). There is considerable awareness among planners in North America and Europe about the ecological implications of traffic engineering projects. Regarding wetlands, stringent policies and rules in the United States protect wetlands during traffic infrastructure construction and traffic operations. The Safe, Accountable, Flexible, Efficient Transportation Equity Act (SAFETEA-LU) of 2005 is meant to protect wetlands as well as other ecosystem components by streamlining transportation infrastructure projects (USDOT 2005). The efforts by the U.S. Department of Transport to implement the provision of this act are complemented by other agencies in the United States. However, such legal safeguards and complementary support systems don't exist in most other countries. In those countries, ecosystem components suffered due to ill-conceived plans and their subsequent execution. Undesired consequences follow unregulated planning and implementation.

There are urgent needs for preventive and remedial measures. Remedial actions typically involve 
much higher costs compared to preventive steps incorporated at the beginning of a project.

\section{Background}

Wetlands are associated with a number of bird and animal species, including elephants. Wetlands are attractive to elephants not only for the water but also as a food source, since wetlands include different species of plants. India has the largest Asiatic elephant (Elephas maximus) population (numbering $21,000-25,000)$ in the world. Assam state in India, which is regarded as one of the strongholds of Asiatic elephants with a population of about 5200 in 2005 (Authors 2006), is considered the key conservation region for the species (Stracey 1963). Overall population of the species is in decline and habitat loss has been cited as one of the major causes of that decline (Leimgruber et al. 2003; Thitaram et al. 2008). Poaching for ivory, human-elephant competition for land and food, and lack of management infrastructure are the other major reasons for elephant population decline. Elephants depend on perennial water sources such as wetlands for food, water, and recreation (Fernando et al. 2008, Mosepele et al. 2009).

\subsection{Genesis of the present problem}

Deepor Beel is one of the largest and most important natural wetlands in the Brahmaputra Valley of lower Assam, India, and is representative of the wetlands found within the Burma Monsoon Forest biogeography region (Saikia and Bhattacharjee 1987). Like other wetlands (Alho and Vieira 1997; Herath 2004), Deepor Beel supplies a diverse group of goods and services to the local community and animal population. The whole wetland $\left(40.14 \mathrm{~km}^{2}\right)$ was declared as a Ramsar site in 2002 (Ramsar 2008b) and $4.14 \mathrm{~km}^{2}$ within the Ramsar site was proposed as a wildlife sanctuary (Government of Assam 1989a). The existence of Deepor Beel and RaniGarbhanga reserved forests $\left(>100 \mathrm{~km}^{2}\right)$ side by side adds to the diversity of wildlife habitats and increases the socioeconomic importance of the wetland. In addition to other birds and animals (Table 1), RaniGarbhanga reserved forests house about 80 to 120 Asiatic elephants (Government of Assam records, unpublished). Deepor Beel is a staging site for migratory birds, and some of the largest congregations of aquatic birds in Assam can be seen here in winter (a record 19,000 water birds for a single-day count). The richness of avian fauna has earned Deepor Beel a place in Birdlife International's list of Important Bird Areas (IBA). The wetland serves as a major fish breeding and nursery ground and supplies fish stocks to other nearby bodies of water (Bezbaruah 2010). Invasive plant species (e.g., Eichhornia crassipes, nee water hyacinth) presently covers more than 50 percent of the $40.14 \mathrm{~km}^{2}$ wetland (Figure 1). There are also a number of socioeconomically important plant species in the area (Table 2).

Table 1. List of International Union for the Conservation of Nature (IUCN) red-listed species found in Deepor Beel wetland (Bezbaruah 2010).

\begin{tabular}{ll}
\hline Common Name & Scientific Name \\
\hline Mammals & \\
Asiatic elephant & Elephas maximus \\
Irriwaddy squirrel & Callosciurus pygerythrus \\
Hoolock gibbon & Hylobates hoolock \\
Birds & \\
Spot-billed pelican & Pelecanus philippensis \\
Baers Pochard & Aythya baeri \\
Lesser Adjutant stork & Javanicus \\
Pallas's Sea Eagle & Haliaeetus leucogaster \\
Slender-billed vulture & Gyps tenuirostris \\
Ferruginous Duck & Aythya nyroca \\
Greater Adjutant stork & Leptoptilos dubius \\
\hline
\end{tabular}



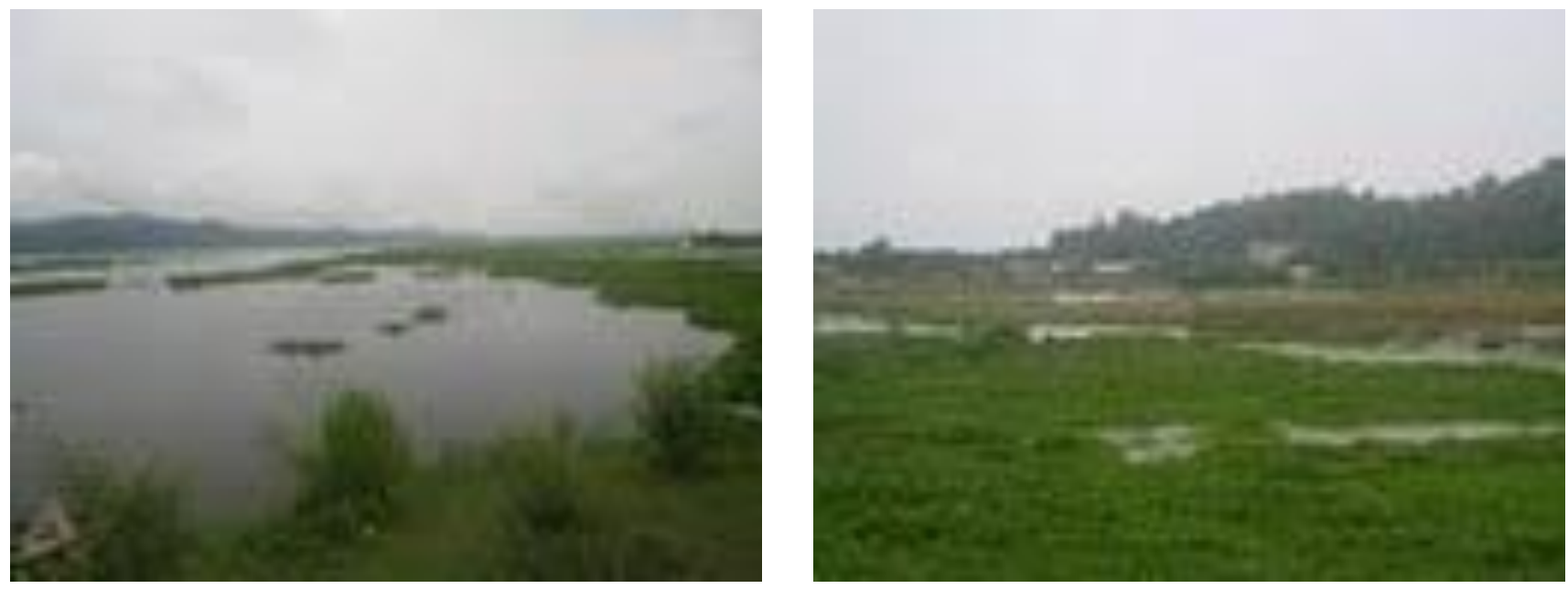

Figure 1. Extent of vegetation in Deepor Beel Wetland

Table 2. List of dominant aquatic, shoreline, and forest vegetation and plants found in and around Deepor Beel area (Islam and Rahmani 2005; Bezbaruah 2010)

\begin{tabular}{ll}
\hline Common Name & Scientific Name \\
\hline Giant water lily & Euryalea ferox \\
Tape grass & Vallisneria spiralis \\
Hydrilla & Hydrilla verticillata \\
Swamp morning glory & Ipomoea reptans \\
Water velvet & Azolla pinnata \\
Giant duckweed & Spirodela polyrhiza \\
Tuberous Indian plantain & Eleocharis plantaginea \\
Water lily & Nymphaea albea \\
Arrowhead & Sagittaria sagittifolia \\
Water hyacinth & Eichhornia crassipes \\
Rice & Oryza sativa \\
Floss flower & Eupatorium odoratum \\
Prickly chaff flower /Latjira & Achyranthes aspera \\
Coco grass/purple nut sedge & Cyperus esculentus \\
Reed & Phragmites karka \\
Chaste tree/Indian privet & Vitex negundo \\
Curry leaf plant & Murraya koenigii \\
Wild sugarcane & Saccharum spontaneum \\
Water lettuce/tropical duckweed & Pistia stratiotes \\
Duck lettuce & Ottelia alismoides \\
Duckweed & Lemna minor \\
Banyan tree & Ficus bengalensis \\
Cotton tree & Bombax malabaricum \\
Belleric myrobalan & Terminalia belerica \\
Teak & Tectona grandis \\
\hline
\end{tabular}

The Northeast Frontier Railway (NFR) constructed Assam state's second railroad (called southern railroad because it is on the south side of the Brahmaputra river) along the southern boundary (and through) Deepor Beel in 2001. This railroad has fragmented the wetland into two major subsystems and also segregated the wetland-forest ecosystem. The Deepor Beel segment of the railroad falls within Kamakhya and Azara stations and is operated by the Rangia division of NFR. An average of 20 passenger trains and 14 freight trains use this track every day. That means one train passes through the Deepor Beel area about every 42 minutes. The rail traffic operates day and night. This number does not include service trains. The rail traffic is expected to increase in the near future given the large quantity of mineral resources (coal, oil, and uranium), agricultural products (rice, tea, fruits, and spices) and forest products (timber and plywood) produced in the region. Before the railroad was constructed the Government of Assam constituted an expert committee to recommend the best alignment so that the environmental damage to the Deepor Beel ecosystem could be minimized. The committee suggested the present southern alignment through RaniGarbhanga reserved forests, despite the fact that the environmental community was against the move. NFR also conducted an independent environmental impact assessment study through Railway India Technical and Economic Services (RITES); results of this study favored a northern alignment that avoided cutting across the wetland (Government of Assam 1990). Two other reports also suggested the northern alignment (APCB 1989; Government of Assam 1989b). The committee's inclination toward the southern alignment was apparently based on the fact that there are educational institutions on the 
northern side and they will be adversely affected by disturbances caused by rail traffic. They failed to recognize the future transportation needs of the area and didn't look into aspects of mass transport via a northern alignment. A number of short- and longterm steps toward achieving a sustainable postrailroad environment were also proposed by the committee as the necessary requirements that should have gone along with the southern alignment. The proposed sustainability measures included scheduling rail traffic to ensure safety to wildlife, installing plantations along the railroad, providing elephants passes in the form of culverts, providing hydraulic structures to ensure free flow of water in the wetland, and banning further development in the wetland.

\section{Research objective and methodology}

\subsection{Development of GIS database}

Satellite images of Deepor Beel and the surrounding area are available from the National Remote Sensing Agency (NRSA), which is an autonomous organization under the Indian Department of Space. In a previous study by Sarma et al. (2008) satellite data provided by Landsat MSS, Landsat Thematic Mapper, and IRS 1D LISS-III were used to assess the changes in forest coverage and to estimate the loss of Asian elephant habitat. Aerial images available from Google Earth have fairly high resolution and are freely available. It, therefore, was decided to use the imagery downloaded from Google Earth for this project with necessary georeferencing of the data. The Google Earth data were also validated with the GPS data available from site surveying. Four control points were used to georeference the Google Earth data (Figure 2). The GCS_India_1975 coordinate system was chosen for this project. The root mean square error of the control points was checked to see whether it was within the tolerance limit. For further validation, some of the GPS data of the site location were brought into this map and checked to see whether they matched with the imagery. After the georeferencing of the imagery was completed, screen digitizing was used to build shape files of important features such as the railroads, highways, and land-use patterns. The wetland was divided into a few zones for the purpose of this analysis.

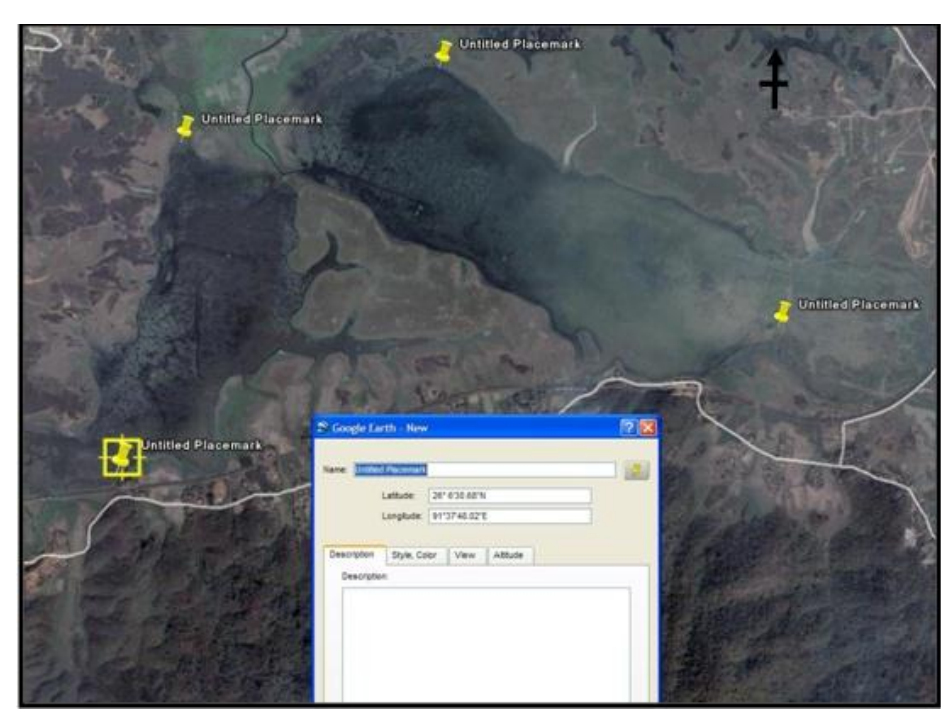

Figure 2. Control points used for georeferencing the Deepor Beel images

\section{$4 \quad$ Habitat evaluation \\ 4.1 Modeling framework}

The habitat evaluation procedure (HEP) used in this study was originally developed by the U.S. Fish and Wildlife Service (USFWS 1980). Daniel and Lamaire (1974) have conceptualized this HEP methodology to numerically measure the quality and quantity of a habitat suitable for a particular species. An index format of habitat measurement is used in the HEP model. In this index format the habitat condition under study is compared to the optimal habitat condition (Innaber 1976). Based on physical and chemical characteristics of the habitat suitable for different species of wildlife, different agencies have developed HSI values. The USFWS has developed charts to measure HSI value for different species.

This HSI value, which is a pure ratio, ranges from 0 to 1 . For the index value of 1 , the study area habitat condition is at its optimum. For an index value of 0 , the condition of the habitat is totally deteriorated and unable to support the concerned species. In the HEP model it is assumed that HSI varies linearly from 1 to 0 . This linearity assumption im- 
plies that the carrying capacity of the habitat has a linear correlation with the index value. An index value of 0.1 and 0.2 signifies 10 percent and 20 percent carrying capacity of the optimal condition. The HEP model uses a "species-habitat" approach to assess the impact on the ecosystem. The index value is a measure of the habitat's ability to support the species, which depends on it for its sustenance. The HEP proposes habitat units as a means of measuring impact of assessment. The product of the suitability index and the area covered by the habitat, supporting a particular species, is a measure of habitat unit for that particular species.

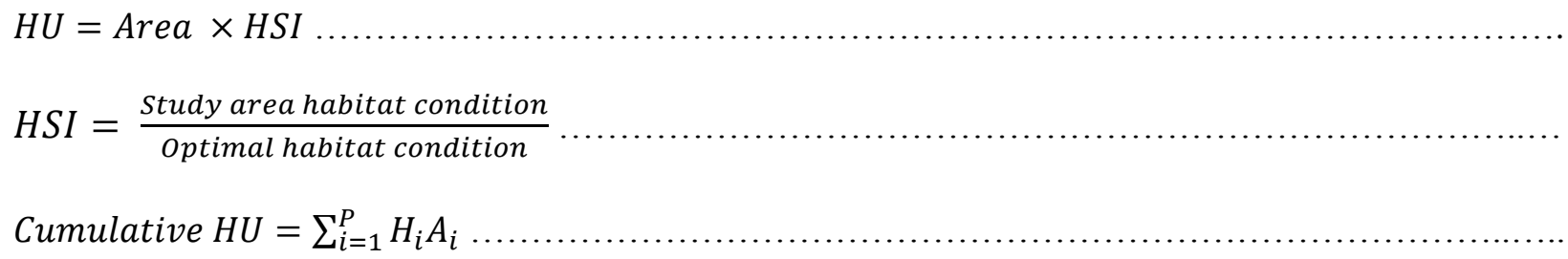

Where

$$
\begin{aligned}
& H U=\text { Habitat } \text { Unit } \\
& H S I=\text { Habitat Suitability Index } \\
& H_{i}=H S I \text { in year } i \\
& A_{i}=\text { area of available habitat in year } i \\
& P=\text { period of analysis }
\end{aligned}
$$

To estimate cumulative $H U$ using Equation 3, the study area is to be divided into small sub-areas and the time scale to be considered should be very small. Knowing precise $H_{i}$ (i.e., HSI value for each individual year) is difficult without acquiring extensive micro-scale monitoring data over time. However, such micro-scale data collection is not required for day-to-day management of the wetland, and it is cost prohibitive to collect such data only for modeling purposes. Also, the values of $H_{i} A_{i}$ from the study area need to be integrated over a longer timescale. As this approach of calculating $H S I$ for each year was difficult in this particular study, an easier quantification approach, Equation 4 (USFWS 2008), was adapted for Deepor Beel. This approach, using the mathematical model in Equation 4, can be easily implemented in other studies with similar ecosystems.

Cumulative $H U=\left(T_{2}-T_{1}\right)\left(\frac{A_{1} H_{1}+A_{2} H_{2}}{3}+\frac{A_{2} H_{1}+A_{1} H_{2}}{6}\right)$

$$
A A H U=\frac{\text { Cumulative } H U}{\left(T_{2}-T_{1}\right)}
$$

Where

$T_{1}=$ first target year of time interval

$T_{2}=$ last target year of time interval

$A_{l}=$ area of available habitat at beginning of time interval

$A_{2}=$ area of available habitat at end of time interval

$H_{1}=$ HSI at beginning of time interval

$\mathrm{H}_{2}=\mathrm{HSI}$ at end of time interval

$A A H U=$ Average annual habitat units 
3 and $6=$ constants derived from integration of HSI x Area for the interval between any two target years The mathematical derivation of Equation 4 is shown in Appendix 1. 


\subsection{Modeling steps}

The steps involved in habitat-based impact assessment (USFWS 2008) are shown in figure 3.

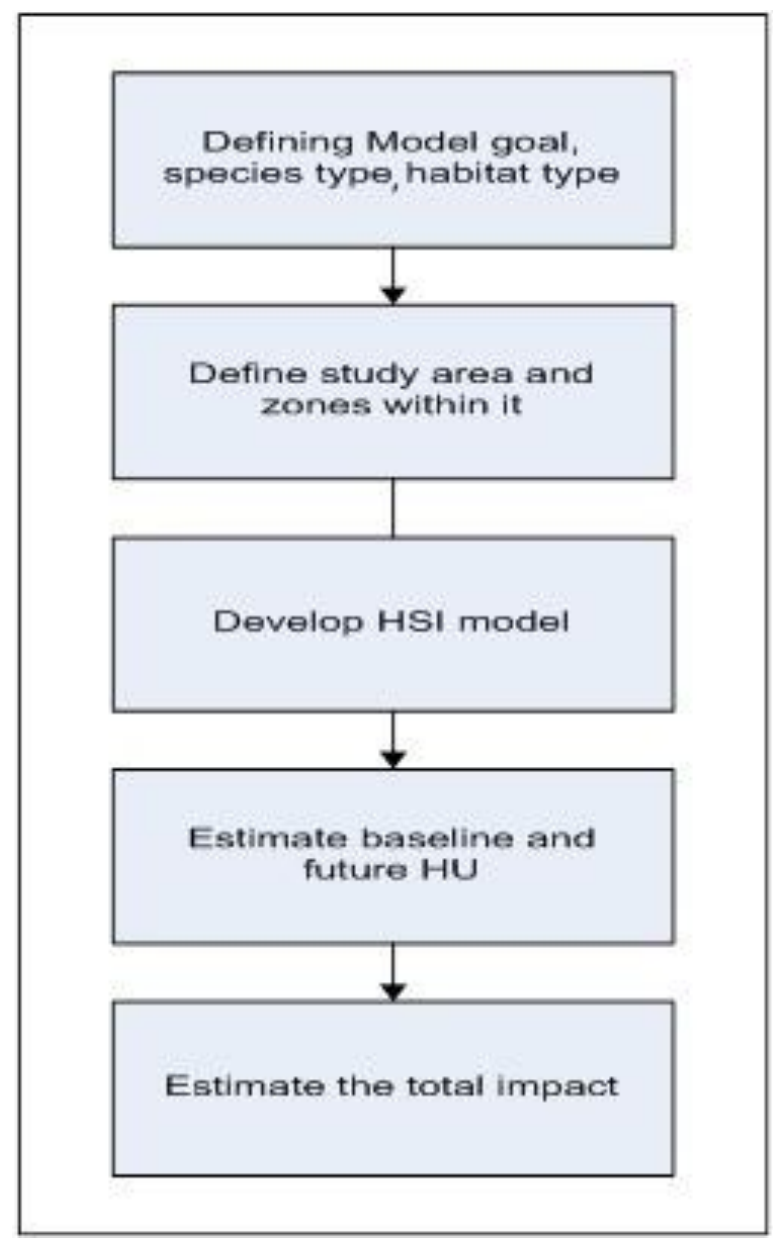

Figure 3. Modeling framework

\subsubsection{Define model goal}

The goal of this research paper is to quantify the impacts of the existing railroad on elephant habitats in the Deepor Beel wetland system using GIS and other modeling tools. This paper may serve as the basis for future analyses of Deepor Beel and similar ecosystems. The models presented in this paper have been kept as simple as possible, with the option of incorporating complexities into them in the future when more detailed data will be available from ongoing research projects. The species for evaluation was selected based on its social and ecological importance. Deepor Beel houses a number of species of birds and animals including endangered Asiatic elephants and a variety of flora including giant water lilies (Euryale ferox) (Saikia and Bhattacharjee 1987; Islam and Rahmani 2005; Bezbaruah 2010). For this project, the Asiatic elephant is selected as the model animal species and giant water lily as the model plant (habitat) species. The Asiatic elephant was selected primarily because of its endangered status. The elephants lack any other major body of water nearby and so must depend on the Deepor Beel wetland to meet their needs. Furthermore, the animal has socioeconomic importance to the villagers living in and around the study area. The giant water lily (Assamese: $m a$ khana) was selected as it is a preferred food of the elephants and is historically abundant in Deepor Beel. Further, giant water lily seeds have economic importance to local people and industries. The authors recognize that use of multiple habitat parameters would have made the model very robust; however, there was not enough data for multi-habitat analysis.

\subsubsection{Define study area}

Deepor Beel wetland is located between $26^{\circ} 06^{\prime} \mathrm{N}$ and $26^{\circ} 09^{\prime} \mathrm{N}$ latitude and $91^{\circ} 36^{\prime} \mathrm{E}$ and $91^{\circ} 41^{\prime} \mathrm{E}$ longitude. The average altitude is 50 to $57 \mathrm{~m}$ above MSL (Saikia and Bhattacharjee 1987). The wetland is situated on the southern bank of the Brahmaputra River and on the southwestern fringe of the city of Guwahati, covering an area of more than $40 \mathrm{~km}^{2}$ (Figure 4). 


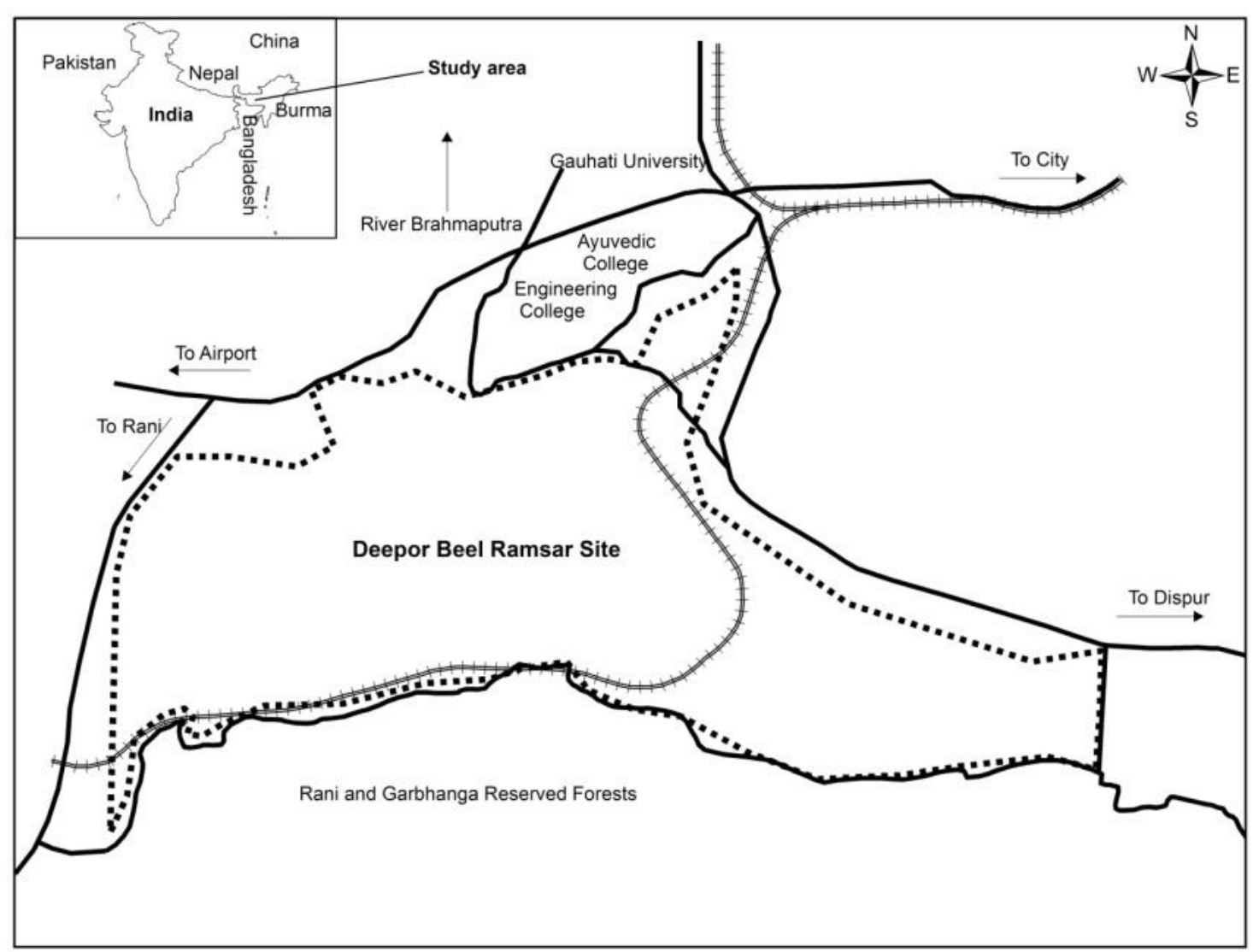

Figure 4. Location map of Deepor Beel wetland and Rani-Garbhanga Reserved Forests; a part of the wetland is shown here.

( $\cdots \cdots$ : Ramsar site boundary, : Railroad, $\longrightarrow$ : Roads/Highways)

The Deepor Beel system is fed by the streams and rivulets flowing from the south and southwestern side of the wetland (Chetry 1999; GOI 2008). Rain and stormwater from the surrounding communities and Guwahati (population $~ 1.5$ million) are also the main sources of flow during the monsoon season (Deka and Goswami 1992). Rivulet Bharalu drains the Guwahati city water into the Brahmaputra during the dry season. However, its sluice-gate is closed during the rainy season, as the Brahmaputra flows above the water level of the Bharalu channel and the city water is diverted to Deepor Beel via the Morabharulu rivulet. The other sources of Deepor waters are the Basistha and Kalmani rivulets and monsoon run-off between May and September from the immediate watershed. At maximum flooding, Deepor Beel is about four meters deep; during the dry season the water depth drops to about one meter. The wetland drains into the Brahmaputra River five kilometers to the north via the Khonajan channel through a sluice-gate at Khanamukh (GOI 2008). Contiguous to Deepor Beel are Rani-Garbhanga Reserved Forests $\left(\sim 232 \mathrm{~km}^{2}\right)$, and they form a unique wetland-forest ecosystem.

\subsubsection{Develop HSI model}

Suitability index (SI) curves, which require elaborate field study, often cannot be completed because of the unavailability of time and resources. In these constrained situations elaborate field tests were substituted with the Delphi technique to develop the index curve. The steps we followed for the Delphi technique were 1) preparing a list of experts in wetland habitat; 2) sending out questionnaires to the experts; 3) tabulating the results of the experts and sending those to the experts for review; and 4) having the experts modify their responses based on aggregate response. The outcome of the Delphi-based HSI curve is shown in figure 5. 


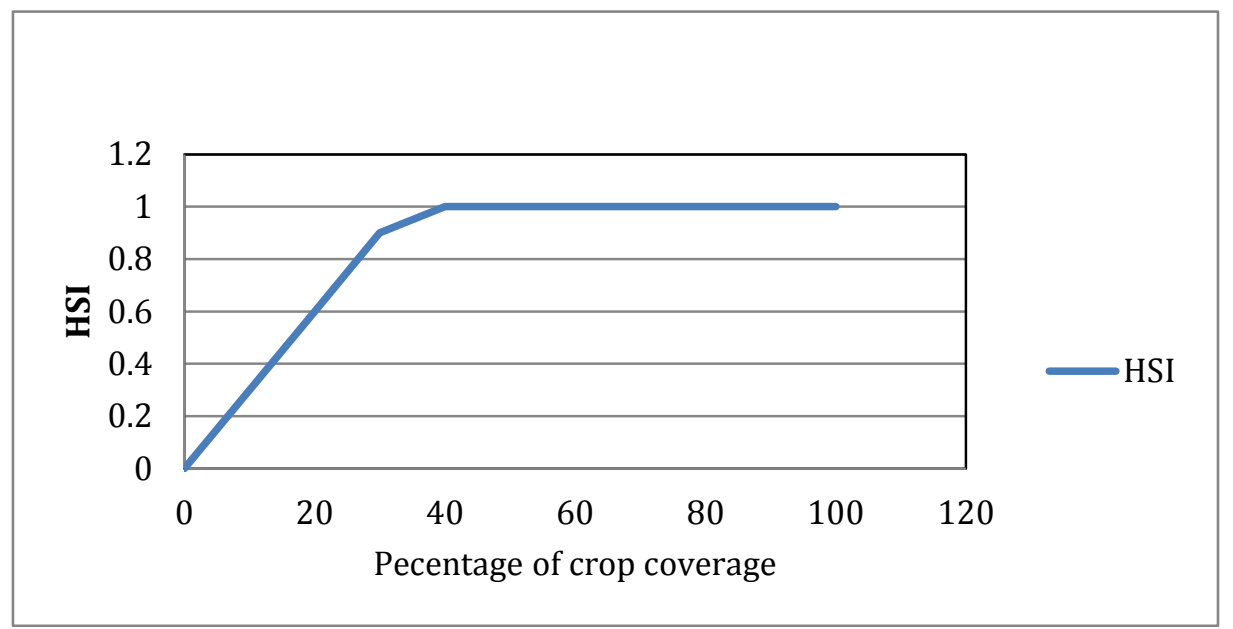

Figure 5. Habitat Suitability Index (HSI) Graph

The crop coverage estimate, which in this case is for the water lily, was done using satellite imagery. Satellite imagery is a rasterized geotiff layer. The crop coverage type was extracted from the satellite imagery mosaic layer by employing an arc object programming developed in visual basic script. This extracted crop layer is converted into an ARC-GIS vector shape file. The vector shape file is overlaid with the section area shape files and the crop coverage area estimated. These estimated crop coverage data are integrated with actual ground data to develop an unbiased estimate of the water lily coverage.

\subsubsection{Define baseline and future $\mathrm{HU}$}

In this analysis 1989 was used as the base year-one year prior to the railroad construction through the main wetland, which started in 1990 . The base year HSI was estimated using the HSI curve developed from the Delphi survey and crop coverage area estimated from the satellite imagery. The first target year was taken as year 1994 (five years from the base year of 1989). Based on time series data and assuming linear trends, the $H_{i}$ and $A_{i}$ were predicted. These two values were used to estimate probable habitat unit (HU) values for the future years. The next target years were 20 (2009) and 50 (2039) years from the base year.

The HSI value for the base year was estimated to be 0.75 . In the first target year-1994-it was observed that for the scenario with railroad construction, the HSI decreased for all six sections. Based on the crop coverage estimated satellite imagery, it was observed that the HSI decreased for all the sections. For sections 1 and 2, this changed HSI value was 0.525 , and for sections 3 through 6 this value was 0.45 . For the scenario without railroad and for the forecasted HSI it was necessary to take recourse of the Delphi survey. The same panel of experts used for developing the HSI graph was used in the survey as well. It was observed based on the Delphi survey data that the HSI value for the target years 20 and 50 were 0.675 and 0.607 , respectively, for the scenario without railroad. The probable cause of this drop in HSI is that the background disturbances in Deepor Beel include the unplanned practice of agriculture and fishing, solid waste and industrial waste dumping, civil construction, top soil removal, and human infringement (Government of Assam 1989b). For the scenario with railroad, the drop in HSI for the target years 20 and 50 was forecasted to be 0.472 for sectors 1 and 2 and 0.36 for sectors 3 through 6 . We have seen that the sectors 3 through 6 have a higher drop in HSI than that of sectors 1 and 2. That is because sectors 3 through 6 have a higher possibility of background disturbance than sectors 1 and 2. Another observation is that the drop in HSI from target year 5 to target year 20 is close to the two scenarios with and without railroad. This implies that the major degradation of the wetland habitat takes place during the first five years from the base year-i.e., the period during the railroad construction.

\subsubsection{Estimate of total impact}

In the analysis two scenarios were considered: 1) habitat in the wetland before railroad construction, 
and 2) habitat in the wetland after railroad construction. Table 3 and Figure 6 present the data analyzed for the six areas into which the study area is divided and a cumulative HU based on Equation 4. The total $\mathrm{HU}$ value remains markedly higher $(\sim 25)$ even after 50 years if it is assumed that there is no railroad in the wetland. However, with the railroad, there is a steep decrease in the value in the first five years, which ultimately goes down to $\sim 14$ in 50 years. The total HU decrease is 43 percent immediately after completion of the railroad (five-year target) and 55 percent over the 50-year target period. The average annual habitat units (AAHU), estimated using Equa- tion 5, show similar trends. The net impact of the railroad was found to be -19.48 (Table 4). This AAHU analysis result helps to reinforce the conclusion that the impact of the railroad on the wetland habitat is significant and undesired. During field visits and imagery analyses, the authors have seen similar impacts in the study area, which were severely affected immediately after railroad construction. In successive years the deterioration continued but with less severity.

Table 3. Pre- and post-railroad construction HSI and HU values for various areas in Deepor Beel (based on Equation 4)

\begin{tabular}{|c|c|c|c|c|c|c|c|c|c|c|c|c|c|c|}
\hline Condition & $\begin{array}{c}\text { Target } \\
\text { Year }\end{array}$ & $\begin{array}{c}\text { Area of } \\
\text { Section } 1 \\
\left(\mathrm{~km}^{2}\right)\end{array}$ & $\begin{array}{c}\text { HSI Val- } \\
\text { ue }\end{array}$ & $\begin{array}{c}\text { Area of } \\
\text { Section } 2 \\
\left(\mathrm{~km}^{2}\right) \\
\end{array}$ & $\begin{array}{c}\text { HSI Val- } \\
\text { ue }\end{array}$ & $\begin{array}{c}\text { Area of } \\
\text { Section } 3 \\
\left(\mathrm{~km}^{2}\right)\end{array}$ & $\begin{array}{c}\text { HSI Val- } \\
\text { ue }\end{array}$ & \begin{tabular}{|c|} 
Area of \\
Section 4 \\
$\left(\mathrm{~km}^{2}\right)$
\end{tabular} & $\begin{array}{c}\text { HSI Val- } \\
\text { ue }\end{array}$ & $\begin{array}{c}\text { Area of } \\
\text { Section } 5 \\
\left(\mathrm{~km}^{2}\right)\end{array}$ & $\begin{array}{c}\text { HSI Val- } \\
\text { ue }\end{array}$ & \begin{tabular}{|c|} 
Area of \\
Section 6 \\
$\left(\mathrm{~km}^{2}\right)$ \\
\end{tabular} & $\begin{array}{c}\text { HSI } \\
\text { Value }\end{array}$ & $\begin{array}{l}\text { Total } \\
\text { HU }\end{array}$ \\
\hline \multirow{4}{*}{$\begin{array}{l}\text { Without } \\
\text { railroad }\end{array}$} & $\begin{array}{c}0 \\
\text { (Base } \\
\text { year) }\end{array}$ & 3.537 & 0.75 & 5.818 & 0.75 & 10.039 & 0.75 & 3.263 & 0.75 & 11.338 & 0.75 & 6 & 0.75 & 29.99 \\
\hline & 5 & 3.537 & 0.75 & 5.818 & 0.75 & 10.039 & 0.75 & 3.263 & 0.75 & 11.338 & 0.75 & 6 & 0.75 & 29.99 \\
\hline & 20 & 3.183 & 0.675 & 5.236 & 0.675 & 10.039 & 0.675 & 3.263 & 0.675 & 11.338 & 0.675 & 6 & $\begin{array}{l}0.67 \\
5\end{array}$ & 26.36 \\
\hline & 50 & 2.864 & 0.607 & 4.712 & 0.607 & 10.039 & 0.675 & 3.263 & 0.675 & 11.338 & 0.675 & 6 & $\begin{array}{l}0.67 \\
5\end{array}$ & 25.28 \\
\hline \multirow{4}{*}{$\begin{array}{l}\text { With } \\
\text { railroad }\end{array}$} & $\begin{array}{c}0 \\
\text { (Base } \\
\text { year) }\end{array}$ & 3.537 & 0.75 & 5.818 & 0.75 & 10.039 & 0.75 & 3.263 & 0.75 & 11.338 & 0.75 & 6 & 0.75 & 29.99 \\
\hline & 5 & 3.183 & 0.525 & 5.236 & 0.525 & 9.02 & 0.45 & 2.33 & 0.45 & 10.624 & 0.45 & 5.957 & 0.45 & 16.98 \\
\hline & 20 & 2.864 & \begin{tabular}{l|}
0.472 \\
5
\end{tabular} & 4.712 & 0.472 & 9.02 & 0.36 & 2.33 & 0.36 & 10.624 & 0.36 & 5.957 & 0.36 & 13.63 \\
\hline & 50 & 2.864 & 0.472 & 4.712 & 0.472 & 9.02 & 0.36 & 2.33 & 0.36 & 10.624 & 0.36 & 5.957 & 0.36 & 13.63 \\
\hline
\end{tabular}




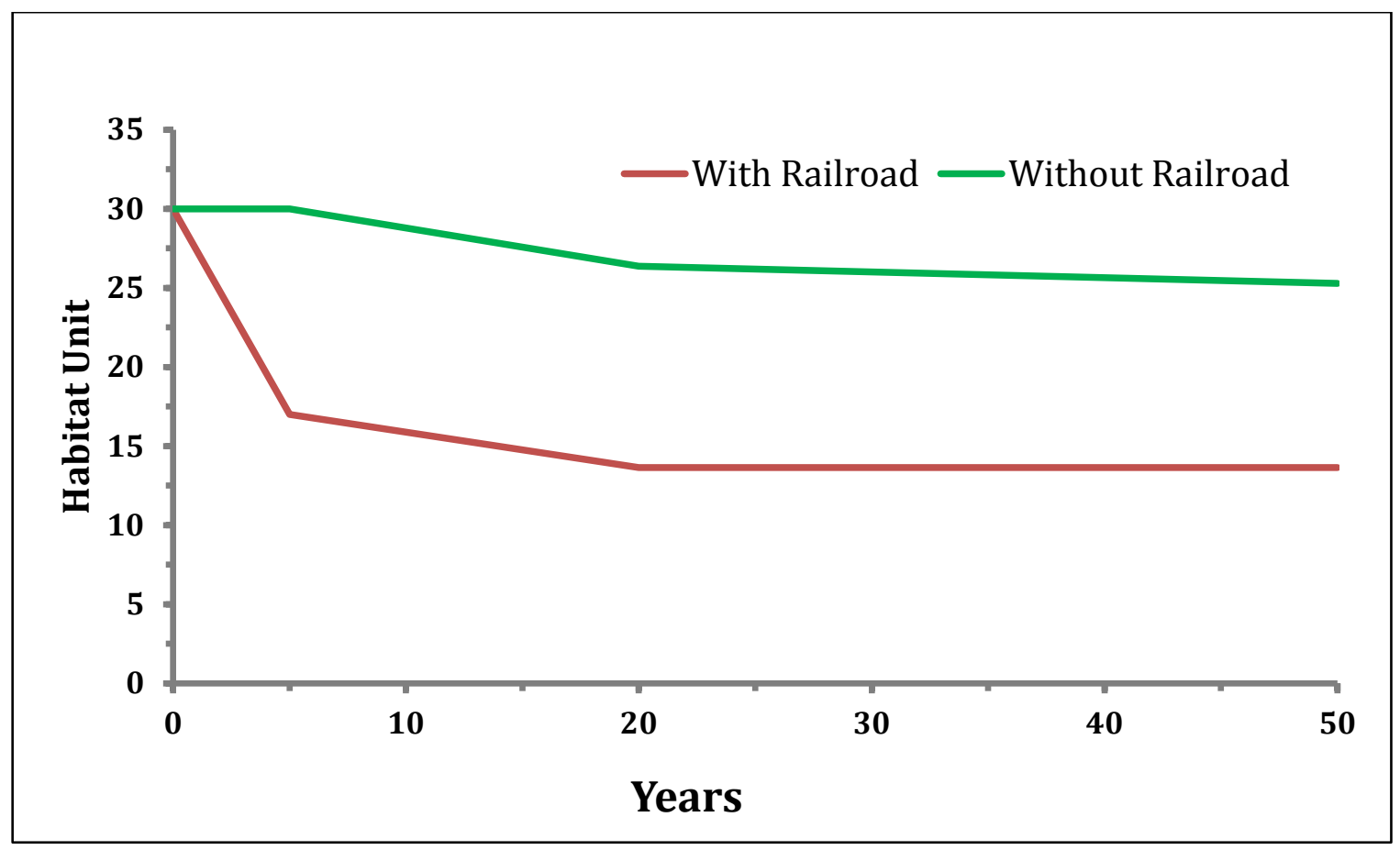

Figure 6. Change of habitat units over time with and without the railroad (based on Table 3)

Table 4. Estimation of net impact as a difference in average annual habitat units (AAHU)

\begin{tabular}{|c|c|c|}
\hline \multirow{2}{*}{ Period $\left(\mathbf{T}_{\mathbf{2}}-\mathbf{T}_{\mathbf{1}}\right)$} & \multicolumn{2}{|c|}{ Cumulative HU } \\
\cline { 2 - 3 } & Without Railroad & With Railroad \\
\hline A & 149.98 & 117.321 \\
\hline B & 563.38 & 313.59 \\
\hline C & 1538.87 & 846.97 \\
\hline AAHU & 45.04 & 25.55 \\
\hline Net Impact $=-19.48$ & \multicolumn{2}{|}{} \\
\hline
\end{tabular}

Note: Period $\mathrm{A}=0-5$ years, Period $\mathrm{B}=5-20$ years, Period $\mathrm{C}=20-50$ years

The embankment created for the railroad has fragmented the wetland into two sub-basins. Hydrology of the wetland has changed because of the embankment, and the smaller basin on the southeast side has virtually become a stagnant pool of water except for small flows through the culverts provided. City stormwater entering from the southeast side via the Morabharalu rivulet has the most unfavorable hydraulic conditions. The rivulet now dumps a huge quantity of nutrient-rich sediments in the smaller sub-basin. Prior to the railroad construction the sediment load was distributed over the wetland and the impact was much less (as can be seen from simulated total HU values in Figure 4). Further, water hyacinth (Eichhornia crassipes), which flourish- es in the wetland, was blown to the shores of the unfragmented wetland by the prevailing wind and occasionally removed or harvested for farming. However, with the railroad, the water hyacinth plants are less affected by the prevailing wind and have become stagnant and growing profusely in the nutrient-rich smaller sub-basin. The nutrient-rich situation in the southeast smaller sub-basin due to the changed hydraulics may lead to enhanced vegetation of other kinds as well. The vegetation growth-deathdegradation cycle may possibly put the wetland in an accelerated eutrophication stage. Changes in species composition and accelerated eutrophication are possible impacts and would need further studies for proper documentation. Our model plant, the giant 
water lily, seems to compete poorly with water hyacinth and other vegetation. Giant water lily growth has decreased significantly in the smaller sub-basin, which has made that part of the wetland unattractive for elephants. Habitat degradation and fragmentation are two of the major threats for the elephant population that uses Deepor Beel wetland. Fragmentation of the original elephant feeding area has been found to have serious implications for the animals' movement and competition with man for food.

\section{Conclusions}

This study demonstrated that GIS techniques can be effectively used in modeling impacts of transportation infrastructure on microenvironments. Although the study used only the elephant and giant water lily for the model, the methodology can be expanded to study a number of other species and socioeconomic and environmental conditions vis-à-vis transportation projects and similar infrastructure projects. GIS has been used by others for elephant corridor status assessment and monitoring (Nandy et al. 2007), but this is, so far, the first time the tool has been used for analyzing the impacts of a railroad project on a natural wetland with specific emphasis on an endangered animal. Unlike many other animals, elephants have vast ranging areas, both inside and outside protected sanctuaries or reserves (Fernando et al. 2008). Thus, it is very common for elephants to enter agricultural areas and destroy crops. The specific modeling techniques presented in this paper may be useful in evaluating large ranging areas of elephants in Asia and Africa.

\section{Acknowledgments}

The authors wish to gratefully acknowledge Northeast Frontier Railways (of Indian Railways) for the data provided. North Dakota State University students (course ECS 740: Environmental Management) worked on Deepor Beel Ramsar wetland as a case study in fall 2007. Information and data collected by the students (available at http://www.ndsu.edu/pubweb/ bezbarua/em/) have been extensively used in this study.

The authors also gratefully thank Adrian $\mathrm{H}$. Farmer, Ph.D., Wild Ecological Solutions, for his help in formulating the basic algorithm for computing cumulative HU.

\section{References}

Alho, C. J. R. and L. M. Vieira. 1997. Fish and wildlife resources in the Pantanal wetlands of Brazil and potential disturbances from the release of environmental contaminants. Environmental Toxicology and Chemistry (16): 71-74.

Allen, A.W. 1983. Habitat suitability index models: Beaver. Washington, DC: United States Fish and Wildlife Service. http://docs.streamnetlibrary.org/USFWS/hsimbeaver.pdf

APCB (Assam Pollution Control Board). 1989. An environmental impact assessment report on Deepor Beel basin area. Guwahati, India.

Bezbaruah, A. N. Deepor Beel Case Study. http://www.ndsu.edu/pubweb/ bezbarua/em/. (Accessed September 2010.)

Brander, L. M., R. Florax, and J. Vermaat. 2006. The empirics of wetland valuation: A comprehensive summary and a meta-analysis of the literature. Environmental \& Resource Economics (33): 223-250. doi: 10.1007/s10640-005-3104-4.

Chetry, G. 1999. Limnology of Deepor Beel with special reference to its biodiversity and pollution status. Dissertation (Ph.D.), Guwahati University, India.

Constanza, R., R. d'Agre, R. de Groot, S. Farber, M. Grasso, B. Hannon, K. Limburg, S. Naeem, R. V. O’Neil, J. Paruelo, R. G. Raskin, P. Sutton, and M. V. D. Belt. 1997. The value of the world's ecosystem services and natural capital." Nature 387: 260-287. doi: 10.1038/387253a0.

Deka, S. K. and D. C. Goswami. 1992. Hydrology, sediment characteristics and depositional environment of wetlands: A case study of Deepor Beel, Assam. Journal of Assam Science Society 34: 62-84.

Drews, C. 1995. Road kills of animals by public traffic in Mikumi National Park, Tanzania, with notes on baboon mortality. African Journal of Ecology 33: 89100. doi: 10.1111/j.1365-2028.1995.tb00785.x.

Fernando, P., E. D. Wikrarnanayake, H. K. Janaka, L. K. A. Jayasinghe, M. Gunawardena, S. W. Kotagama, D. Weerakoon and J. Pastorini. 2008. Ranging behavior of the Asian elephant in Sri Lanka. Mammalian Biology 73: 2-13. doi:10.1016/j.mambio.2007.07.007.

Government of Assam. 1989a. The Assam Gazette (March 12), Assam, India.

Government of Assam. 1989b. Report on broad gauge railway line through the Deepor Beel. Assam, India.

Government of Assam. 1990. Report of the committee on environmental implications associated with the B.G. railway alignment through the Deepor Beel area. Assam, India. 
Gurluke, S., and E. Rehber. 2006. Evaluation of an integrated wetland management plan: Case of Uluabat (Apollonia) Lake, Turkey. Wetlands 26: 258-264. doi:10.1672/0277-

5212(2006)26[258:EOAIWM]2.0.CO;2.

Herath, G. 2004. Incorporating community objectives in improved wetland management: The use of the analytic hierarchy process. Journal of Environmental Management 70: 263-273. doi: 10.1016/j.jenvman.2003.12.011.

Huijser, M.P., P. McGowen, J. Fuller, A. Hardy, A. Kociolek, A.P. Clevenger, D. Smith and R. Ament. 2008. Wildlife-vehicle collision reduction study: Report to Congress. Washington, DC: US Department of Transportation Federal Highway Administration. http://www.fhwa.dot.gov/publications/research/safety/08 034/.

Islam M. Z. and A. R. Rahmani. 2005. Important bird areas in India: Priority sites for conservation. Oxford University Press, Oxford, UK.

Jabareen, Y. R. 2006. Sustainable urban forms Their typologies, models, and concepts." Journal of Planning Education and Research 26: 38-52. doi:10.1177/0739456X05285119.

Kushwaha, S. P. S. and R. Hazarika. 2004. Assessment of habitat loss in Kameng and Sonitpur Elephant Reserves. Current Science 87:1447-1453.

Leimgruber, P., J. B. Gagnon, C. Wemmer, D. S. Kelly, M. A. Songer, and E. R. Selig. 2003. Fragmentation of Asia's remaining wild lands: implications for Asian elephant conservation. Animal Conservation 6: 347-359. doi:10.1177/0739456X05285119.

Maltby, E. 1991. Wetland management goals-Wise use and conservation. Landscape and Urban Planning 20: 9-18. doi: 10.1016/0169-2046(91)90085-Z.

Mosepele, K., Moyle, P. B., Merron, G. S., Purkey, D. R. and Mosepele, B. 2009. Fish, floods, and ecosystem engineers: Aquatic conservation in the Okavango Delta, Botswana." Bioscience, 59:53-64. doi: 10.1525/bio.2009.59.1.9.
Nandy, S., S. P. S. Kushwaha, and S. Mukhopadhyay. 2007. Monitoring the Chilla-Motichur wildlife corridor using geospatial tools. Journal for Nature Conservation 15:237-244. doi: 10.1016/j.jnc.2007.03.003.

Ramsar. 2008a.The Ramsar Convention on Wetlands. http://www.ramsar.org/pdf/sitelist.pdf. (Accessed September 2010.)

Ramsar. 2008b.The list of wetlands of international importance. http://www.ramsar.org/pdf/sitelist.pdf. (Accessed September 2010.)

Reinelt, E. L., J. Velikanje and J. E. Bell. 1991. Development and application of geographic information system for wetland/watershed analysis. Computer, Environment and Urban Systems 15(4):239-251. doi: 10.1016/0198-9715(91)90029-D.

Saikia, P. K. and P. C. Bhattacharjee. 1987. A study of the avifauna of Deepor Beel: A potential bird sanctuary in Assam. Asian Wetland Bureau, Kuala Lumpur, Malaysia.

Sinha, K. C. and S. Labi. 2007. Transportation decision making: Principles of project evaluation and programming. New Jersey: John Wiley \& Sons.

Stracey, P. D. 1963. Elephant gold. London: Weidenfeld and Nicolson.

Authors. 2006. Site visit by one or more authors.

Thitaram, C., N. Thongtip, C. Somgird, B. Colenbrander, D. C. J. van Boxtel, F. Van Steenbeek, and J. A. Lenstra. 2008. Evaluation and selection of microsatellite markers for an identification and parentage test of Asian elephants. Conservation Genetics 9, 921-925. doi: 10.1007/s10592-007-9406-z.

United States Department of Transportation (n.d.). USDOT full text of SAFETEA-LU and the related congressional reports. Washington DC. https://www.fhwa.dot.gov/safetealu/legis.htm.

United States Fish and Wildlife Service. 2008. $\mathrm{Na}$ tional wetlands inventory habitat evaluation procedures handbook. Washington, DC. 


\section{Appendix A}

In HEP, cumulative habitat units is computed by summing the area under a plot of HU versus time. This is equivalent to the mathematical integration of the HU relationship over time, or

$$
\text { Cumul at } i \text { ve } H U=\int_{0}^{T} H U d t
$$

But $H U=A \times H$ where $A$ is habitat area and $H$ is the habitat suitability index. Also, over any time interval of length $T\left(=T_{2}-T_{1}\right)$ within which $A$ and $H$ either change linearly or not at all, the value of $\mathrm{A}$ and $\mathrm{H}$ is given by

$$
\begin{aligned}
& A=A_{l}+m_{1} t \\
& H=H_{1}+m_{2} t
\end{aligned}
$$

where $t$ is time, $A_{l}$ is the area at the beginning of the time interval, $H_{l}$ is the habitat suitability index at the beginning of the time interval, $m_{1}$ is the rate of change of area with time, and $m_{2}$ is the rate of change of habitat suitability with time. Thus

$$
\begin{aligned}
\int_{0}^{T} H U d t & \equiv \int_{0}^{T}\left(A_{1}+m_{1} t\right)\left(H_{1}+m_{2} t\right) d t \\
& \equiv \int_{0}^{T} A_{1} H_{1} d t+\int_{0}^{T} m_{1} H_{1} t d t+\int_{0}^{T} m_{2} A_{1} t d t+\int_{0}^{T} m_{1} m_{2} t^{2} d \imath \\
& \equiv A_{1} H_{1} T+\frac{m_{1} H_{1} T^{2}}{2}+\frac{m_{2} A_{1} T^{2}}{2}+\frac{m_{1} m_{2} T^{3}}{3}
\end{aligned}
$$

Substitute the following equations for the slopes $m_{1}$ and $m_{2}$

$$
\begin{aligned}
& m_{1}=\frac{A_{2}-A_{1}}{T} \\
& m_{2}=\frac{H_{2}-H_{1}}{T}
\end{aligned}
$$

into the above to get

$$
\int_{0}^{T} H U d \equiv A_{1} H_{1} T+\frac{\left(A_{2}-A_{1}\right) H_{1} T}{2}+\frac{\left(H_{2}-H_{1}\right) A_{1} T}{2}+\frac{\left.\left(A_{2}-A_{1}\right) H_{2}-H_{1}\right) T}{3}
$$

Collecting terms, substituting $\left(T_{2}-T_{1}\right)$ for $T$, and simplifying yields

$$
\int_{0}^{T} H U d \equiv\left(T_{2}-T_{1}\right)\left[\left(\frac{A_{1} H_{1}+A_{2} H_{2}}{3}\right)+\left(\frac{A_{2} H_{1}+A_{1} H_{2}}{6}\right)\right]
$$

